\title{
Inflammation in HIV Positive Non Hodgkin Lymphoma Patients
}

\author{
Brian Thabile Flepisi ${ }^{1 *}$, Patrick Bouic ${ }^{2}$, Gerhard Sissolak ${ }^{3}$ and Bernd Rosenkranz ${ }^{4}$ \\ ${ }^{1}$ Department of Medical Biosciences, University of the Western Cape, South Africa \\ ${ }^{2}$ Department of Medical Microbiology, Stellenbosch University, South Africa \\ ${ }^{3}$ Department of Medicine, Division of Clinical Haematology, Stellenbosch University, South Africa \\ ${ }^{4}$ Department of Medicine, Stellenbosch University, South Africa
}

Submission: April 03, 2017; Published: May 24, 2017

*Corresponding authors: Brian Thabile Flepisi, Department of Medical Biosciences, University of the Western Cape, South Africa, Tel: +27-21-959-2186/+27-73-999-9026; Fax: +27-21-959-3125; Email: brianflepisi@gmail.com

\begin{abstract}
Background: HIV-1 infection is associated with dysregulation of cytokine production and this is thought to contribute to HIV associated immune deficiency. The dysregulation of cytokine production may be playing a role in the pathogenesis of HIV+ NHL, as evidenced by increased prevalence of NHL in HIV-1 infection. This study aimed to determine the serum concentrations of circulating inflammatory cytokines and the effect of cART in HIV positive NHL patients.

Methods: The serum concentrations of IFN- $\gamma$, IL-1 $\beta$, IL-2, IL-4, IL-6, IL-8, IL-10, IL-12p70, IL-13, and TNF- $\alpha$ were determined by mesoscale discovery (MSD) assay in 141 subjects that were divided into 5 groups: naive HIV+ ; cART treated HIV+ ; HIV negative NHL; HIV+ NHL and healthy controls.

Results: HIV+ NHL patients had higher serum concentrations of IL-4 as compared to NHL and HIV+ cART patients. As compared to NHL patients, the serum concentrations of IL-2, and TNF- $\alpha$ were significantly higher in HIV+ NHL patients, while those of IL-1 $\beta$ were significantly lower. HIV+ NHL patients had higher serum concentrations of IFN- $\gamma$, and IL-6; and lower serum concentrations of IL-12p70 than HIV+ cART patients. All the inflammatory cytokines were significantly increased in NHL as compared to the controls, as well as in cART-naïve HIV+ patients as compared to HIV+ cART and controls.
\end{abstract}

Conclusion: The serum concentrations of inflammatory cytokines are increased in HIV positive NHL patients. This suggests that chronic inflammation may play a role in the pathogenesis of lymphoma.

Keywords: HIV; Non Hodgkin's lymphoma; Inflammation; Cytokines

Abbreviations: NHL: Non Hodgkin Lymphoma; cART: combination Antiretroviral Therapy; HIV+ NHL: HIV Positive Non Hodgkin Lymphoma; HIV-NHL : HIV Negative Non Hodgkin Lymphoma ; MSD: Meso-Scale Discovery

\section{Introduction}

The majority of people with HIV live in sub-Saharan Africa, with South Africa having the highest number of cases recorded world-wide [1,2]. Haematological manifestations of HIV including Non Hodgkin lymphoma (NHL) are common and diverse, and can occur at all stages of infection [3]. Preliminary studies conducted in South Africa suggest that HIV associated lymphomas are increasing in number with increasing HIV prevalence [1]. However, accurate epidemiologic, aetiologic and clinical data of HIV+ NHL is limited in Sub-Saharan Africa.

The inflammatory response triggered by infection precedes tumor development and is part of the normal host defence against pathogens [4]. Inflammation is recognized as a hallmark feature of cancer development and progression [5]. The hallmarks of cancer related inflammation include the presence of inflammatory cells and inflammatory mediators (such as chemokines, cytokines and prostaglandins) in tumor tissues, tissue remodelling and angiogenesis similar to that seen in chronic inflammatory responses and tissue repair [6]. It has been suggested that local inflammatory processes and antigenic drive can promote lymphoma development at the site of inflammation/immune activation [7]. The current study aimed to determine the serum concentrations of circulating inflammatory cytokines in HIV+ NHL patients; and to determine whether combination antiretroviral therapy (cART) has an impact on the serum concentrations of inflammatory cytokines. 
Materials and Methods

\section{Study population}

Study populations consisted of 141 participants divided into 5 groups consisting of HIV positive Non Hodgkin lymphoma $(\mathrm{HIV}+\mathrm{NHL})$ patients $(\mathrm{n}=31)$, HIV negative NHL (NHL) patients $(\mathrm{n}=34)$, combination antiretroviral therapy (cART) treated HIV positive (HIV+ cART) patients $(n=32)$, cART-naïve HIV positive (cART-naïve HIV+) patients $(\mathrm{n}=28)$, and a healthy control group (Controls) $(\mathrm{n}=16)$. Participants were 18 years old and above, and were age and gender matched.

\section{Determination of serum concentrations of inflammatory cytokines}

Meso-scale discovery (MSD) pro-inflammatory panel 1 (human) kit was used to determine the serum concentrations of IFN- $\gamma$, IL-1 $\beta$, IL-2, IL-4, IL-6, IL-8, IL-10, IL-12p70, IL-13, and TNF- $\alpha$ as follows. $50 \mu$ l of the diluted samples ( 2 fold), calibrators and controls were added into each well respectively. The plate was sealed with an adhesive plate sealer and incubated at room temperature with shaking for 2 hours. Following the incubation, the plate was washed 3 times with $150 \mu$ l/well of wash buffer. $25 \mu$ l of the detection antibody solution was added into each well and the plate was sealed with adhesive plate sealer and incubated at room temperature with shaking for 2 hours. Following the incubation, the plate was washed 3 times with wash buffer. $150 \mu \mathrm{l}$ of $2 x$ read buffer Twin was added into each well and the plate was read on the MSD instrument.

\section{Ethical considerations}

This study was approved by the health research ethics committee at Stellenbosch University (N12/03/015) and University of Cape Town (076/2013). All participants completed and signed the informed consent forms, which were available in English, Afrikaans and Xhosa. The study was carried out in accordance with the Helsinki Declaration.

\section{Statistical analysis}

The data obtained was captured using Microsoft Excel and Graph pad prism version 5 was used to analyse the data. The analysis of the primary objective was performed by using a one-way ANOVA. The study populations were regarded as the independent variables and the specific marker value was regarded as the dependent variable. Relationship between two continuous variables was analysed with regression analysis and the strength of the relationship measured with the Pearson correlation, or Spearman correlation. A p-value of $\mathrm{p}<0.05$ represented statistical significance in hypothesis testing and $95 \%$ confidence intervals was used to describe the estimation of unknown parameters.

\section{Results}

\section{Serum concentrations of circulating interferon gamma (IFN- $\gamma$ )}

Therewasnosignificant differencein the serum concentrations of circulating IFN $-\gamma$ when HIV positive NHL (HIV+ NHL) patients were compared to HIV negative NHL (NHL) patients (Figure 1). The serum concentrations of circulating IFN- $\gamma$ were significantly higher in HIV+ NHL patients than HIV positive patients on a cART regimen (HIV+ cART) $(26.719 \pm 25.632$ vs $10.458 \pm 8.920)$. NHL patients had significantly higher serum concentrations of circulating IFN- $\gamma$ than controls $(20.425 \pm 29.907$ vs $5.734 \pm 2.328)$. As compared to cART-naïve HIV+ patients, HIV+ cART patients had significantly lower serum concentrations of circulating IFN- $\gamma$ $(10.458 \pm 8.920$ vs $33.067 \pm 9.340)$. cART-naïve HIV+ patients had significantly higher serum concentrations of circulating IFN $-\gamma$ than controls $(33.067 \pm 9.340$ vs $5.734 \pm 2.328)$. The serum concentrations of circulating IFN- $\gamma$ were negatively correlated with the numbers of CD4 T-cells $(r=-0.4369, p<0.0001)$, NKTcells $(r=-0.2460, p=0.0139)$, and FoxP3 expression $(r=-0.2891$, $\mathrm{p}=0.0047$ ) (Table 1). However, these serum concentrations of circulating IFN- $\gamma$ were positively associated with the number of CD8 T-cells ( $r=0.2200, p=0.0250)$, NK-cells ( $r=0.1903, p=0.0454)$, and CD8+CD38 expression $(\mathrm{r}=0.4919, \mathrm{p}<0.0001)$ (Table 1$)$.

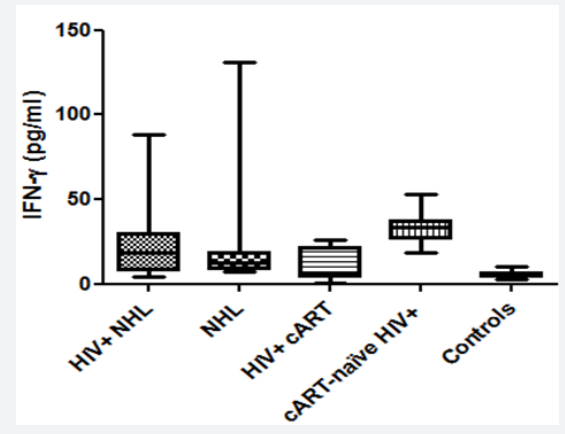

Figure 1: Serum concentrations of circulating interferon gamma (IFN-y).

HIV+NHL, HIV positive non-Hodgkin lymphoma patients $(\mathrm{n}=31)$;

$\mathrm{NHL}$, HIV negative non-Hodgkin lymphoma patients $(n=34)$;

HIV+ cART, combination antiretroviral therapy treated (cART) HIV positive individuals $(\mathrm{n}=32)$;

cART-naïve HIV+, cART-naïve HIV positive individuals ( $n=28$ ); Controls, Healthy controls $(n=16)$.

Table 1: Significant correlations of inflammatory cytokines.

\begin{tabular}{|c|c|c|c|c|c|c|c|}
\hline & CD4 & CD8 & CD19 & NKT & NK & FoxP3 & CD38 \\
\hline IFN- $\gamma$ & - & + & & - & + & - & + \\
\hline IL-1 $\beta$ & & & - & & & & + \\
\hline IL-2 & - & + & - & - & & - & + \\
\hline IL-4 & - & & - & - & + & - & + \\
\hline IL-6 & - & & - & - & & - & + \\
\hline IL-8 & - & & - & - & & & + \\
\hline IL-10 & & & & & + & & + \\
\hline IL-12p70 & - & + & - & & + & - & + \\
\hline IL-13 & - & & & & & & + \\
\hline TNF- $\alpha$ & - & + & - & & + & - & + \\
\hline
\end{tabular}

-: Negative association; +: Positive association; IFN-ץ: Interferon gamma; IL-1ß: Interleukin-1ß; IL-4: Interleukin-4; IL-6: Interleukin-6; 
IL-8: Interleukin-8; IL-10: Interleukin-10; IL-12p70: Interleukin-12p70; IL-13: Interleukin-13; TNF- $\alpha$ : Tumor necrosis factor- $\alpha$; Natural killer T-cells; Natural killer cells.

\section{Serum concentrations of circulating interleukin-1 $\beta$ (IL-1ß)}

The serum concentrations of circulating interleukin- $1 \beta$ were significantly lower in HIV positive NHL (HIV+ NHL) patients as compared to HIV negative NHL (NHL) patients $(0.117 \pm 0.083$ vs $0.196 \pm 0.096$ ) (Figure 2). However, there was no significant difference in the serum concentrations of circulating IL-1 $\beta$ when HIV+ NHL were compared with HIV positive patients on a cART regimen (HIV+ cART). The serum concentrations of circulating IL-1 $\beta$ were significantly higher in NHL patients than controls $(0.196 \pm 0.096$ vs $0.102 \pm 0.078)$. As compared to cART-naïve HIV+ patients, HIV+ cART patients had significantly lower serum concentrations of circulating IL- $1 \beta(0.113 \pm 0.079$ vs $0.201 \pm 0.180)$. In addition, cART-naïve HIV+ patients had higher serum concentrations of circulating IL- $1 \beta$ than controls $(0.201 \pm 0.180$ vs $0.102 \pm 0.078$ ). The serum concentrations of circulating IL- $1 \beta$ were positively associated with $\mathrm{CD} 8+38$ expression $(\mathrm{r}=0.3384$, $\mathrm{p}=0.0011$ ), while they were negatively associated with CD19+ B-cells ( $r=-0.2778, p=0.0063$ ) (Table 1).

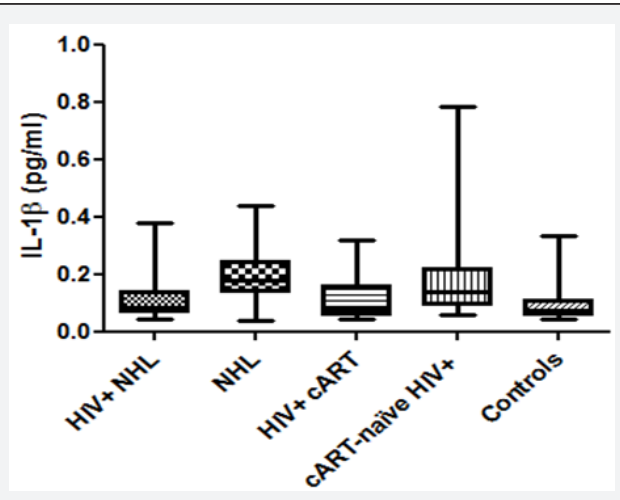

Figure 2: Serum concentrations of circulating interleukin-1 $\beta$ (IL-1 $\beta$ ).

HIV+NHL, HIV positive non-Hodgkin lymphoma patients $(n=31)$;

$\mathrm{NHL}$, HIV negative non-Hodgkin lymphoma patients $(n=34)$;

HIV+ cART, combination antiretroviral therapy treated (cART) HIV positive individuals $(n=32)$;

cART-naïve HIV+, cART-naïve HIV positive individuals $(n=28)$;

Controls, Healthy controls $(n=16)$.

\section{Serum concentrations of circulating interleukin-2 (IL-} 2)

The serum concentrations of circulating interleukin-2 (IL2) were significantly higher in HIV positive NHL (HIV+ NHL) patients when compared to HIV negative NHL (NHL) patients $(0.356 \pm 0.135$ vs $0.249 \pm 0.116)$ (Figure 3 ). However, there was no significant difference in the serum concentrations of circulating IL-2 between HIV+ NHL and HIV positive patients on a cART regimen (HIV+ cART). NHL patients had significantly higher serum concentrations of circulating IL-2 than controls
$(0.249 \pm 0.116$ vs $0.077 \pm 0.044)$. The serum concentrations of circulating IL-2 were significantly lower in HIV+ cART than cART-naïve HIV+ patients $(0.328 \pm 0.148$ vs $0.714 \pm 0.338)$. cART-naïve HIV+ patients had significantly higher serum concentrations of circulating IL- 2 than controls $(0.714 \pm 0.338$ vs $0.077 \pm 0.044$ ). The serum concentrations of circulating IL-2 were negatively associated with the numbers of CD4 T-cells ( $r=-$ 0.4860, $\mathrm{p}<0.0001), \mathrm{CD} 19+\mathrm{B}$-cells ( $\mathrm{r}=-0.3892, \mathrm{p}=0.0002)$, NKTcells $(r=-0.2315, p=0.0194)$, and FoxP3 expression ( $r=-0.4406$ $\mathrm{p}<0.0001$ ), while they were positively associated with the numbers of CD8 T-cells ( $\mathrm{r}=0.3135, \mathrm{p}=0.0023)$ and CD8+CD38 expression ( $\mathrm{r}=0.4014, \mathrm{p}=0.0001)$ (Table 1$)$.

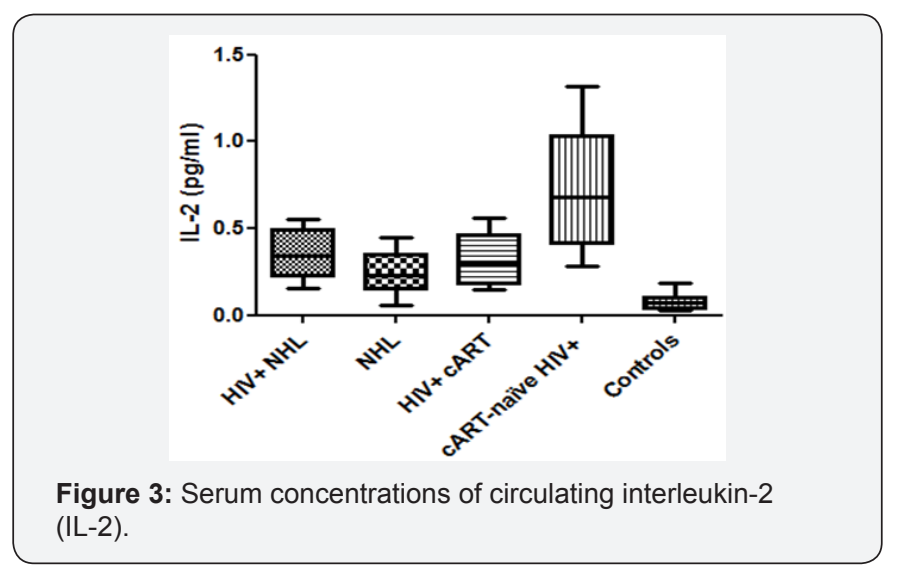

HIV+NHL, HIV positive non-Hodgkin lymphoma patients $(n=31)$; $\mathrm{NHL}$, HIV negative non-Hodgkin lymphoma patients $(n=34)$; $\mathrm{HIV}+\mathrm{cART}$, combination antiretroviral therapy treated (cART) HIV positive individuals $(n=32)$;

cART-naïve HIV+, cART-naïve HIV positive individuals $(n=28)$; Controls, Healthy controls $(n=16)$.

\section{Serum concentrations of circulating interleukin-4 (IL- 4)}

The serum concentrations of circulating interleukin-4 (IL4) were significantly higher in HIV positive NHL (HIV+ NHL) patients as compared to both HIV negative NHL (NHL) patients $(0.102 \pm 0.036$ vs $0.081 \pm 0.016)$ and HIV positive patients on a cART regimen (HIV+ cART) $(0.102 \pm 0.036$ vs $0.081 \pm 0.026)$ (Figure 4). As compared to the controls, NHL patients had significantly higher serum concentrations of circulating IL-4 $(0.081 \pm 0.016$ vs $0.056 \pm 0.030)$. HIV+ cART patients had significantly lower serum concentrations of circulating IL-4 as compared to cART-naïve HIV+ patients $(0.081 \pm 0.026$ vs $0.112 \pm 0.042$ ). In addition, cART-naïve HIV+ patients had higher serum concentrations of circulating IL-4 than controls $(0.112 \pm 0.042$ vs $0.056 \pm 0.030)$. The serum concentrations of circulating IL-4 were negatively associated with the numbers of CD4 T-cells ( $\mathrm{r}=-0.4603, \mathrm{p}<0.0001), \mathrm{CD} 19+\mathrm{B}$-cells ( $\mathrm{r}=-$ $0.3070, p=0.0028)$, NKT-cells ( $r=-0.2249, p=0.0224$ ) and FoxP3 expression $(\mathrm{r}=-0.3077, \mathrm{p}=0.0028)$, while they were positively associated with the numbers of NK-cells $(r=0.2853, p=0.0052)$, and CD8+CD38 expression ( $\mathrm{r}=0.3220, \mathrm{p}=0.0018)$ (Table 1$)$. 


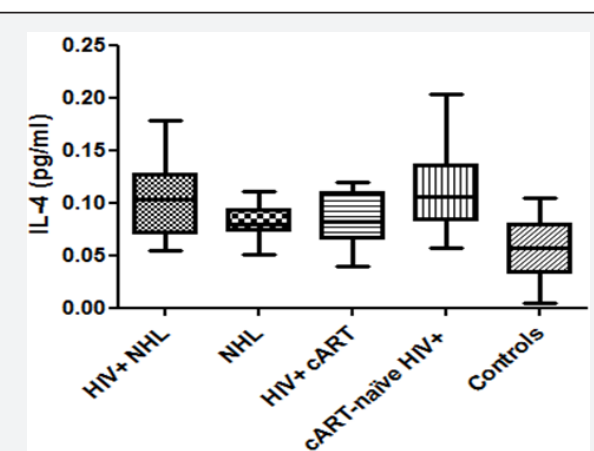

Figure 4: Serum concentrations of circulating interleukin-4 (IL-4).

HIV+NHL, HIV positive non-Hodgkin lymphoma patients $(n=31)$; NHL, HIV negative non-Hodgkin lymphoma patients $(n=34)$; HIV+ cART, combination antiretroviral therapy treated (CART) HIV positive individuals $(n=32)$;

cART-naïve HIV+, cART-naïve HIV positive individuals $(n=28)$;

Controls, Healthy controls $(n=16)$.

\section{Serum concentrations of circulating interleukin-6 (IL-} 6)

There was no significant difference in the serum concentrations of circulating interleukin-6 (IL-6) between HIV positive NHL (HIV+ NHL) patients and HIV negative NHL (NHL) patients (Figure 5). The serum concentrations of circulating IL-6 were significantly higher in HIV+ NHL patients when compared to HIV positive patients on a cART regimen (HIV+ cART) $(1.473 \pm 1.256$ vs $0.779 \pm 0.268)$. NHL patients had higher serum concentrations of circulating IL- 6 than controls $(1.179 \pm 1.171$ vs $0.415 \pm 0.190$ ). The serum concentrations of circulating IL- 6 were significantly lower in HIV+ cART as compared to cARTnaïve HIV+ patients $(0.779 \pm 0.268$ vs $2.447 \pm 1.350)$. In addition, cART-naïve HIV+ patients had significantly higher serum concentrations of circulating IL- 6 than controls $(2.447 \pm 1.350$ vs $0.415 \pm 0.190$ ). The serum concentrations of circulating IL- 6 were negatively associated with the numbers of CD4 T-cells ( $\mathrm{r}=-$ 0.5432, $\mathrm{p}<0.0001), \mathrm{CD} 19+\mathrm{B}$-cells ( $\mathrm{r}=-0.4544, \mathrm{p}<0.0001)$, NKTcells $(\mathrm{r}=-0.2616, \mathrm{p}=0.0095)$, and FoxP3 expression $(\mathrm{r}=-0.399$, $\mathrm{p}=0.0001)$, while they were positively associated with $\mathrm{CD} 8+38$ expression $(r=0.4139, \mathrm{p}<0.0001)$ (Table 1$)$.

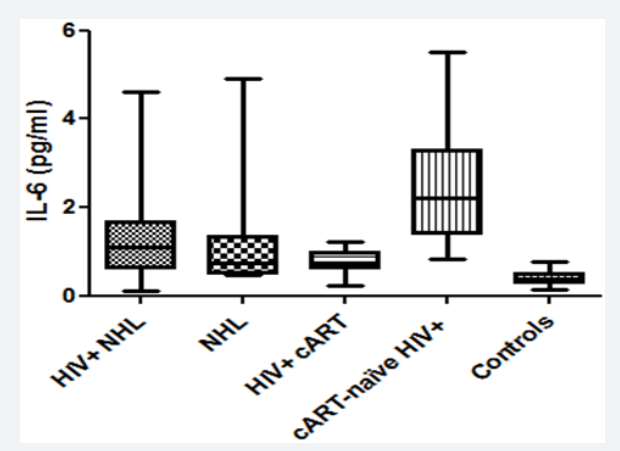

Figure 5: Serum concentrations of circulating interleukin-6 (IL-6).
HIV+NHL, HIV positive non-Hodgkin lymphoma patients $(n=31)$; NHL, HIV negative non-Hodgkin lymphoma patients $(n=34)$; $\mathrm{HIV}+\mathrm{cART}$, combination antiretroviral therapy treated (cART) HIV positive individuals $(n=32)$;

cART-naïve HIV+, cART-naïve HIV positive individuals ( $n=28$ ); Controls, Healthy controls $(n=16)$.

\section{Serum concentrations of circulating interleukin-8 (IL-} 8)

There was no significant difference in the serum concentrations of circulating interleukin-8 (IL-8) when HIV positive NHL (HIV+ NHL) and HIV negative NHL (NHL) patients were compared (Figure 6). HIV+ NHL patients had significantly higher serum concentrations of circulating IL-8 than HIV positive patients on a cART regimen (HIV+ cART) $(13.027 \pm 5.341$ vs $9.615 \pm 5.483$ ). The serum concentrations of circulating IL-8 were significantly up-regulated in NHL patients as compared to controls $(13.942 \pm 7.602$ vs $9.110 \pm 2.733)$. HIV+ cART patients had significantly lower serum concentrations of circulating IL-8 as compared to cART-naïve HIV+ patients $(9.615 \pm 5.483$ vs $14.002 \pm 3.649$ ). cART-naïve HIV+ patients had significantly higher serum concentrations of circulating IL-8 than controls $(14.002 \pm 3.649$ vs $9.110 \pm 2.733)$. The serum concentrations of circulating IL-8 were negatively associated with the numbers of CD4 T-cells ( $r=-0.3819, \mathrm{p}=0.0002), \mathrm{CD} 19+\mathrm{B}$-cells ( $\mathrm{r}=-0.4411$, $\mathrm{p}<0.0001)$ and NKT-cells $(\mathrm{r}=-0.3472, \mathrm{p}=0.0008)$, while they were positively associated with $\mathrm{CD} 8+\mathrm{CD} 38$ expression $(\mathrm{r}=0.4357$, $\mathrm{p}<0.0001$ ) (Table 1).

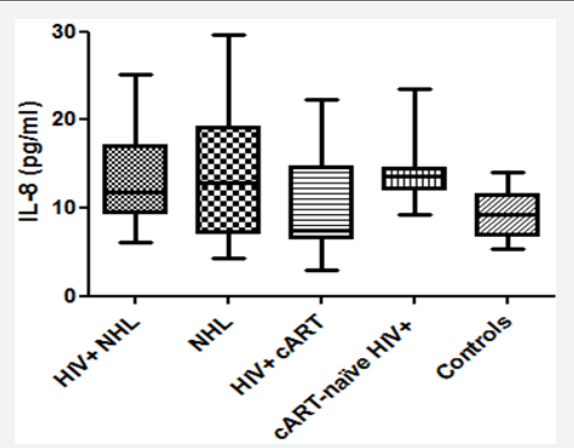

Figure 6: Serum concentrations of circulating interleukin-8 (IL-8).

HIV+NHL, HIV positive non-Hodgkin lymphoma patients $(n=31)$; $\mathrm{NHL}$, HIV negative non-Hodgkin lymphoma patients $(n=34)$; HIV+ CART, combination antiretroviral therapy treated (cART) HIV positive individuals $(n=32)$;

cART-naïve HIV+, cART-naïve HIV positive individuals $(n=28)$;

Controls, Healthy controls $(n=16)$.

\section{Serum concentrations of circulating interleukin-10 (IL-10)}

There was no significant difference in the serum concentrations of circulating interleukin-10 (IL-10) between HIV positive NHL (HIV+ NHL) and HIV negative NHL (NHL) patients (Figure 7). The serum concentrations of circulating IL-10 were 
significantly higher in HIV+ NHL than HIV positive patients on a cART regimen (HIV+ cART) $(1.119 \pm 0.691$ vs $0.482 \pm 0.210)$. NHL patients had significantly higher serum concentrations of circulating IL-10 than controls $(1.344 \pm 1.550$ vs $0.375 \pm 0.338)$. HIV+ cART patients had significantly lower serum concentrations of circulating IL-10 than cART-naïve HIV+ patients $(0.482 \pm 0.210$ vs $1.312 \pm 0.569$ ). The serum concentrations of circulating IL10 were significantly higher in cART-naïve HIV+ patients as compared to controls $(1.312 \pm 0.569$ vs $0.375 \pm 0.338)$. The serum concentrations of circulating IL-10 were positively associated with the numbers of NK-cells ( $\mathrm{r}=0.2086, \mathrm{p}=0.0317)$ and CD8+38 expression ( $\mathrm{r}=0.3521, \mathrm{p}=0.0007$ ) (Table 1$)$.

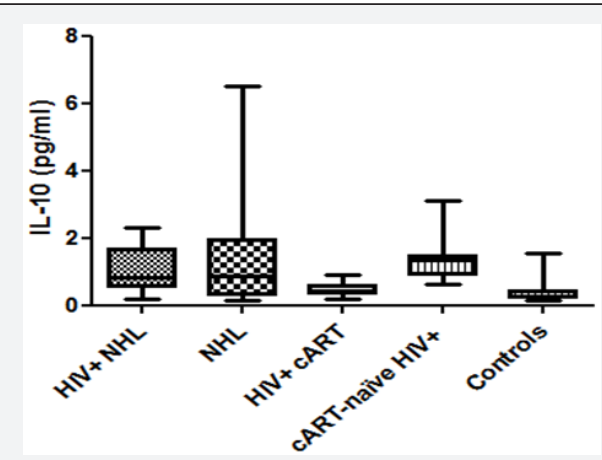

Figure 7: Serum concentrations of circulating interleukin-10 (IL-10).

HIV+NHL, HIV positive non-Hodgkin lymphoma patients $(n=31)$; NHL, HIV negative non-Hodgkin lymphoma patients $(n=34)$; HIV+ cART, combination antiretroviral therapy treated (cART) HIV positive individuals $(\mathrm{n}=32)$;

cART-naïve HIV+, cART-naïve HIV positive individuals ( $n=28$ ); Controls, Healthy controls $(n=16)$.

Serum concentrations of circulating interleukin12 p70 (IL-12p70)

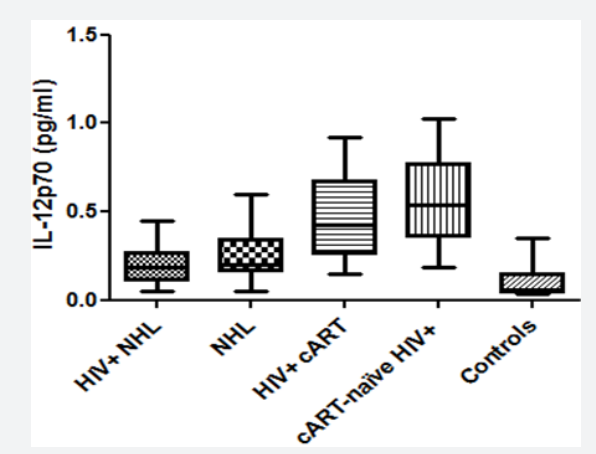

Figure 8: Serum concentrations of circulating interleukin-12p70 (IL-12p70).

HIV+NHL, HIV positive non-Hodgkin lymphoma patients $(n=31)$;

NHL, HIV negative non-Hodgkin lymphoma patients $(n=34)$;

HIV+ CART, combination antiretroviral therapy treated (cART) HIV positive individuals $(n=32)$;

cART-naïve HIV+, cART-naïve HIV positive individuals ( $n=28)$;

Controls, Healthy controls $(n=16)$.

There was no significant difference in the serum concentrations of circulating interleukin-12p70 (IL-12p70) when HIV positive NHL (HIV+ NHL) and HIV negative NHL (NHL) patients were compared (Figure 8). HIV+ NHL patients had significantly lower serum concentrations of circulating IL-12p70 than HIV positive patients on a cART regimen (HIV+ cART) $(0.198 \pm 0.115$ vs $0.459 \pm 0.226)$. The serum concentrations of circulating IL-12p70 were significantly higher in NHL patients as compared to controls $(0.250 \pm 0.143$ vs $0.101 \pm 0.091)$. There was no significant difference in the serum concentrations of circulating IL-12p70 between HIV+ cART and cART-naïve HIV+ patients. cART-naïve HIV+ patients had significantly higher serum concentrations of circulating IL-12p70 than controls $(0.576 \pm 0.245$ vs $0.101 \pm 0.091)$. The serum concentrations of circulating IL-12p70 were negatively associated with the numbers of CD4 T-cells ( $\mathrm{r}=-0.3439, \mathrm{p}=0.0009), \mathrm{CD} 19+\mathrm{B}$-cells $(\mathrm{r}=-0.4269, \mathrm{p}<0.0001)$, and FoxP3 expression $(\mathrm{r}=-0.3615$, $\mathrm{p}=0.0005)$, while they were positively associated with the numbers of CD8 T-cells ( $r=0.2449, p=0.0143)$, NK-cells ( $r=0.195$, $\mathrm{p}=0.0415)$, and CD8+CD38 expression $(\mathrm{r}=0.2245, \mathrm{p}=0.0227)$ (Table 1).

\section{Serum concentrations of circulating interleukin-13 (IL-13)}

There was no significant difference in the serum concentrations of circulating interleukin-13 (IL-13) when HIV positive NHL (HIV+ NHL) and HIV negative NHL (NHL) patients were compared, as well as between HIV+ NHL and HIV positive

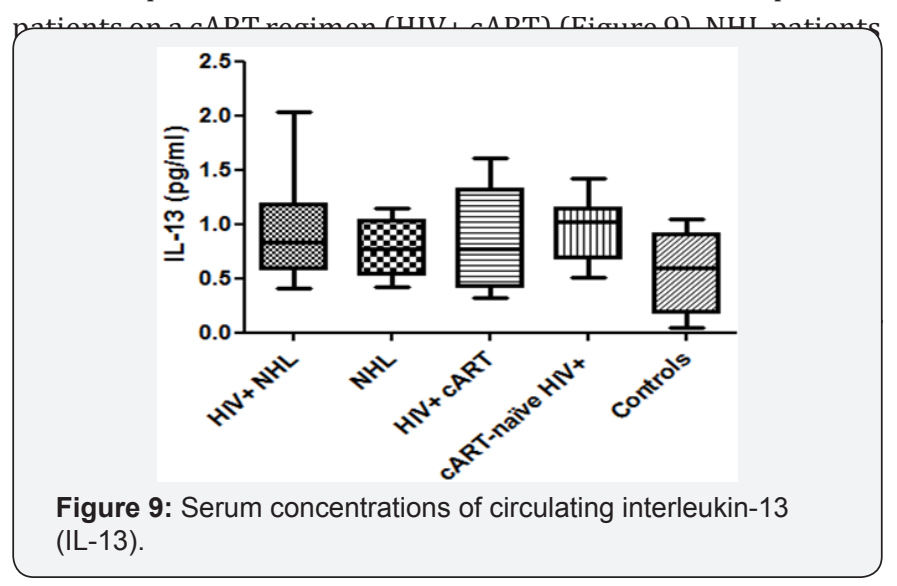

HIV+NHL, HIV positive non-Hodgkin lymphoma patients $(n=31)$; NHL, HIV negative non-Hodgkin lymphoma patients $(n=34)$;

$\mathrm{HIV}+\mathrm{cART}$, combination antiretroviral therapy treated (cART) HIV positive individuals $(n=32)$;

cART-naïve HIV+, cART-naïve HIV positive individuals ( $n=28$ );

Controls, Healthy controls $(n=16)$. 
Serum concentrations of circulating tumor necrosis factor- $\alpha$ (TNF- $\alpha)$

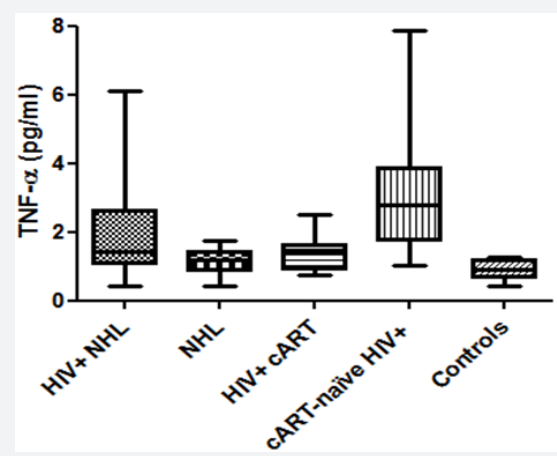

Figure 10: Serum concentrations of circulating tumor necrosis factor- $\alpha(T N F-\alpha)$.

HIV+NHL, HIV positive non-Hodgkin lymphoma patients $(\mathrm{n}=31)$;

NHL, HIV negative non-Hodgkin lymphoma patients $(\mathrm{n}=34)$;

HIV + cART, combination antiretroviral therapy treated

(cART) HIV positive individuals $(n=32)$;

cART-naïve HIV+, cART-naïve HIV positive individuals $(\mathrm{n}=28)$;

Controls, Healthy controls $(\mathrm{n}=16)$.

The serum concentrations of circulating tumor necrosis factor- $\alpha$ (TNF- $\alpha$ ) were significantly higher in HIV positive NHL (HIV+ NHL) patients as compared to HIV negative NHL (NHL) patients $(2.012 \pm 1.581$ vs $1.144 \pm 0.394)$ (Figure 10). However, there was no significant difference in the serum concentrations of TNF- $\alpha$ between HIV+ NHL patients and HIV positive patients on a cART regimen (HIV+ cART). As compared to the controls, NHL patients had significantly higher serum concentrations of circulating TNF- $\alpha(1.144 \pm 0.394$ vs $0.925 \pm 0.268)$. The serum concentrations of circulating TNF- $\alpha$ were significantly lower in HIV+ cART patients than cART-naïve HIV+ patients $(1.342 \pm 0.465$ vs $3.198 \pm 2.029$ ). In addition, cART-naïve HIV+ patients had significantly higher serum concentrations of circulating TNF- $\alpha$ than controls $(3.198 \pm 2.029$ vs $0.925 \pm 0.268)$. The serum concentrations of circulating TNF- $\alpha$ were negatively associated with the number of CD4 T-cells ( $r=-0.4508, p<0.0001)$, CD19+ B-cells $(\mathrm{r}=-0.3782, \mathrm{p}=0.0003)$, and FoxP3 expression $(\mathrm{r}=-$ $0.4322, \mathrm{p}<0.0001$ ), while they were positively correlated with the numbers of CD8 T-cells ( $r=0.2243, p=0.0227)$, NK-cells $(\mathrm{r}=0.2101, \mathrm{p}=0.0307)$ and $\mathrm{CD} 8+\mathrm{CD} 38$ expression $(\mathrm{r}=0.2661$, $\mathrm{p}=0.0085)$ (Table 1).

\section{Discussion}

\section{Interferon gamma (IFN- $\gamma$ )}

IFN- $\gamma$ is known to have a major effect on the regulation of antigen presentation by macrophages, dendritic cells, and in induction of class switching of B-cells [8,9]. IFN- $\gamma$ production is detected as early as the acute phase in HIV-1 infected patients, and is known to play various roles in the pathogenesis of HIV disease [10]. In the current study, the serum concentrations of circulating IFN- $\gamma$ were significantly increased in HIV+ NHL as compared to HIV+ cART patients. However, there was no significant difference in the serum concentrations of circulating IFN- $\gamma$ when HIV + NHL patients were compared to NHL patients (Figure 1). Although there was no significant difference in the serum concentrations of circulating IFN- $\gamma$ between HIV+ NHL and $\mathrm{NHL}$, there was a trend towards increased serum concentrations in HIV+ NHL. In addition, NHL had high serum concentrations of circulating IFN- $\gamma$ when compared to the control population.

IFN- $\gamma$ plays an important role in tumor protection and rejection [11], thus the observed increased serum concentrations of circulating IFN- $\gamma$ in NHL may have been due to the immune system trying to eradicate malignant lymphoma cells. Gergely et al. [12] reported that IFN- $\gamma$ production by peripheral T-cell subsets is increased in B-cell NHL patients and this may contribute to strong polarization towards T-helper cell 1 (TH1) type response necessary for lymphoma clearance and remission. The serum concentrations of circulating IFN- $\gamma$ were significantly elevated in cART-naïve HIV+ patients as compared to HIV+ cART patients as well as when compared to the controls (Figure 1). These findings suggest that HIV-1 infection increases the serum concentrations of circulating IFN- $\gamma$ and cART reduces them. This may not be a direct effect of cART to the serum concentrations of circulating IFN $-\gamma$, but rather an indirect effect of decreasing the viral load. In addition, the serum concentrations of circulating IFN $-\gamma$ were negatively associated with the numbers of CD4 T-cells, NKT-cells and FoxP3 expression, while they were positively associated with the numbers of CD8 T-cells, NK-cells and CD8+CD38 expression (Table 1). These results suggest that the decreased immune regulation may lead to increased IFN- $\gamma$ expression and immune activation.

IFN- $\gamma$ is initially produced to clear the primary HIV1 infection, however, the increased serum concentrations observed in the current study may contribute in establishing a chronic immune activation that exacerbates HIV+ NHL [10]. This is reflected in the increased CD8+CD38 expression, reduced FoxP3 and CD4 T-cell counts in this patient population group. The increased immune activation is a hallmark feature of both HIV disease and NHL. However, the serum concentrations of circulating IFN- $\gamma$ were positively associated with CD8 T-cells and NK-cells, thus it may enhance cytotoxic T-cell and NK-cell activities against HIV-1 infected cells and malignant lymphoma cells [10]. In addition, NK-cells are known to produce IFN- $\gamma$, thus the increased serum concentrations of circulating IFN $-\gamma$ may have been caused by increased NK-cell expression.

\section{Interleukin-1 beta (IL-1 $\beta$ )}

IL-1 $\beta$ enhances antibody production of B-cells and promotes B-cell proliferation [13]. Elevated IL-1 $\beta$ expression has been 
associated with several diseases including cancer $[13,14]$. In the current study, the serum concentrations of circulating IL$1 \beta$ in HIV+ NHL were investigated. The serum concentrations of circulating IL-1 $\beta$ were significantly reduced in HIV+ NHL as compared to NHL and there was no significant difference when compared to HIV+ cART patients (Figure 2). NHL patients had increased serum concentrations of circulating IL-1 $\beta$ when compared to the controls (Figure 2). IL-1 $\beta$ is known to promote $\mathrm{B}$-cell proliferation and differentiation hence its expression is increased in B-cell NHL [13]. HIV-1 infection did not influence the serum concentrations of circulating IL- $1 \beta$ in NHL patients in the current study.

cART-naïve HIV+ patients had increased serum concentrations of circulating IL-1 $\beta$ when compared to the controls (Figure 2). In addition, cART-naïve HIV+ patients had elevated serum concentrations of circulating IL-1 $\beta$ than HIV+ cART patients (Figure 2). The observed increased serum concentrations of circulating IL-1 $\beta$ may have been influenced by HIV-1 infection. It has been previously shown that the HIV1 induces IL-1 $\beta$ expression and this is associated with the progression of HIV disease [15]. It has been reported that HIV-1 interacts with chromosome 2 to inhibit IL-1 receptor antagonist, leading to increased IL-1 $\beta$ production [16]. cART has reduced the serum concentrations of circulating IL-1 $\beta$ in HIV+ patients in the current study. High concentrations of IL- $1 \beta$ have been observed in HIV-1 infection and cART reduces IL-1 $\beta$ as a result of increased availability of IL-1 $\beta$ receptor antagonist [17]. Sadeghi et al. [18] demonstrated that cART suppresses the constitutive production of IL-1 $\beta$ in HIV-1 infected patients. Increased serum concentrations of circulating IL- $1 \beta$ were positively associated with CD8+CD38 expression, while they correlated negatively with CD19+ B-cells in the present study (Table 1). Thus it increased with increasing T-cell activation in HIV+ patients. Using HIV-1 transfected cultured human astrocytes, Mamik et al. [19] reported an increase in CD8+CD38 expression in IL-1 $\beta$ activated astrocytes. Therefore, the increased serum concentrations of circulating IL- $1 \beta$ observed in the current study, may have also led to increased T-cell activation. This may be detrimental to the immune system and may pinpoint the origin of chronic immune activation.

\section{Interleukin-2 (IL-2)}

IL-2 plays a role in the stimulation of activated T-cell proliferation, cytotoxic activity of CD8 T-cells and NK-cells $[20,21]$. In addition, IL-2 induces B-cells, and monocytes $[20,21]$. In the current study, the serum concentrations of circulating IL-2 in HIV+ NHL were investigated. The serum concentrations of circulating IL-2 were significantly increased in HIV+ NHL as compared to NHL (Figure 3). As mentioned previously, IL-2 induces SCD23 expression, thus, the increased serum concentrations of circulating sCD23 that were observed in HIV+ NHL patients may have been induced by increased
IL-2 concentrations, thus contributing to chronic B-cell activation. However, there was no significant difference in serum concentrations of circulating IL-2 between HIV+ NHL and HIV+ cART patients.

In addition, NHL had increased serum concentrations of circulating IL-2 as compared to the controls (Figure 3), while cART-naïve HIV+ patients had higher serum concentrations of circulating IL-2 as compared to both HIV+ cART and the controls. These findings indicate that the serum concentrations of circulating IL-2 are greatly increased in NHL as well as in HIV+ state. In consistence, David and colleagues [22], showed that IL-2 receptor expression in HIV+ patients with high viral load is greatly increased as compared to uninfected control individuals. In the same study, cART significantly reduced IL-2R expression in treated HIV+ patients [22]. IL-2 is involved in B-cell differentiation and proliferation, thus it may lead to expansion of EBV positive B-cells resulting in B-cell NHL development [23]. In a study conducted by Cozen et al. [24], it was reported that IL-2 concentrations were significantly higher in lymphoma cases as compared to un-infected controls.

The serum concentrations of circulating IL-2 were negatively associated with the number of CD4 T-cells, NKT-cells and FoxP3 expression in the current study, while they were positively correlated with increased numbers of CD8 T-cells and T-cell activation (Table 1), confirming the increased immune activation that is stimulated by IL-2. It has been reported that IL-2 supports the growth of cytotoxic (CD8) T-cells and is essential for the induction of lymphokine activated killer cells [20]. Thus the increased serum concentrations of circulating IL-2 may play a role in the anti-tumor activities. In addition, IL-2 stimulates the proliferation of activated T-cells, the observed increased serum concentrations may contribute to the chronic immune activation seen in both HIV-1 infection and NHL. The increased IL-2 stimulates immune activation with CD8+CD38 and this is further promoted by reduced FoxP3 expression that normally regulates T-cell activation. cART may reduce the serum concentrations of circulating IL-2 in HIV+ patients which in turn decreases immune activation. In contrast to the current findings IL-2 therapy has been reported to increase CD4 T-cell counts in HIV-1 infected patients $[25,26]$. In addition, it has been reported that IL-2 therapy in HIV+ lymphoma patients may have a role in the prevention and treatment of HIV-1 associated lymphomas [27].

\section{Interleukin-4 (IL-4)}

IL-4 is known to stimulate B-cell activation and differentiation [28]. Its expression may explain the increased B-cell activation seen in HIV+ NHL patients. In the current study, the serum concentrations of circulating IL-4 were significantly increased in HIV+ NHL as compared to NHL as well as when compared to HIV+ cART patients (Figure 4). In addition, the serum concentrations of circulating IL-4 were significantly increased in 
NHL as compared to the controls. These results suggest that the serum concentrations of circulating IL-4 are greatly increased in HIV+ NHL as well as in the HIV negative NHL patients. Thus serum concentrations of circulating IL-4 are increased in NHL regardless of the HIV status and this is because IL-4 is needed for normal growth of B-cells [29]. Gergely et al. [12], reported that the frequency of CD4+ IL-4 expression is significantly higher in NHL patients as compared to controls and treatment with CHOP reduces its expression. To determine the effect of HIV-1 infection as well as the effect of cART on the serum concentrations of circulating IL-4, cART-naïve HIV+ and HIV+ cART patients were compared.

The serum concentrations of circulating IL-4 were significantly higher in cART-naïve HIV+ patients as compared to HIV+ cART patients, as well as when compared to the controls (Figure 4). These results suggest that HIV-1 infection increases serum concentrations of circulating IL- 4 and cART use decreases them. Using peripheral blood mononuclear cells, Valentin and colleagues [30], showed that IL-4 activates HIV-1 expression and controls viral evolution and phenotypic switch that leads to accelerated disease progression. Kazazi et al. [31], showed that IL-4 stimulates HIV-1 replication in the early phases of infection and may also facilitate virus transmission by aggregate formation.

The increased serum concentrations of circulating IL-4 may have led to chronic B-cell activation observed in NHL and $\mathrm{HIV}+$ patients. In addition, increased serum concentrations of circulating IL-4 were associated with decreased numbers of CD4 T-cells, NKT-cells and FoxP3 expression, while they were also associated with increased numbers of NK-cells and CD8 T-cell activation (Table 1). In addition, the serum concentrations of IL- 4 were independently associated with HIV+ NHL. This confirms the role played by HIV-1 in promoting immune activation while reducing immune tolerance and regulation.

\section{Interleukin-6 (IL-6)}

IL-6 has a wide variety of activities, including B-cell stimulation, monocyte differentiation and induction of IL-4 producing cells $[17,21]$. In addition, IL-6 is involved in tumor growth, malignant differentiation of cancer cells and immunemodulation of the micro-environment [32]. In the current study, the serum concentrations of circulating IL- 6 were significantly increased in HIV+ NHL as compared to HIV+ cART patients, however, there was no significant difference when compared to NHL (Figure 5). Although there was no significant difference in the serum concentrations of circulating IL- 6 between HIV+ NHL and NHL, there was a trend towards increased concentrations in HIV+ NHL.

In addition, the serum concentrations of circulating IL- 6 were significantly elevated in NHL when compared to the controls (Figure 5). The increased serum IL-6 concentrations have been associated with elevated cancer risk, and these concentrations were found to be a prognostic factor for several cancer types [32]. In addition, the elevated serum IL-6 concentrations have been previously found to be associated with the subsequent development of B-cell lymphomas in HIV-1 infected patients [33]. Furthermore, Denizot et al. [34], showed that serum IL-6 expression is significantly higher in NHL patients as compared to the healthy controls. The effect of HIV-1 infection and cART on the serum concentrations of circulating IL-6 were also investigated in the current study. The serum concentrations of circulating IL- 6 were significantly increased in cART-naïve HIV+ patients as compared to HIV+ cART patients as well as when compared to the control individuals (Figure 5).

These results imply that HIV-1 infection increased the serum concentrations of circulating IL- 6 and that cART use reduced them. This confirms that cART reduced HIV-1 viral load which decreased with serum concentrations of circulating IL-6. It has been shown that IL-6 can induce HIV-1 expression by acting at the transcriptional or post-transcriptional concentrations in infected monocytic cells [35]. During the acute stage of an infection, relatively high concentrations of IL- 6 are produced and this is important in the activation of T-cells and increasing the number of antibody producing plasma cells against HIV-1 [36]. However, increased concentrations of IL-6 which induce B-cell activation may contribute to chronic B-cell activation. The increased serum concentrations of circulating IL-6 were negatively associated with CD4 T-cell count, CD19, NKT and FoxP3 expression, while they were positively correlated with CD8+CD38 expression (Table 1).

These findings further confirm the increased B-cell activation in HIV+ patients. The negative associations with the numbers of CD4 T-cells, CD19+ B-cells, NKT-cells and FoxP3 expression observed in this study, suggest that IL- 6 weakens the immune system of HIV+ patients. The increased T-cell activation with increasing IL-6 concentrations observed may also contribute to the depletion of the immune function, as it leads to immune exhaustion and T-cell turnover. It has been reported that chronically high concentrations of IL- 6 may weaken the immune system in HIV-1 infected patients and these concentrations were also associated with $40 \%$ increased risk for developing cancer [36]. Furthermore, high IL-6 expression has been associated with increased HIV-1 replication [37] and the development of lymphoma in HIV-1 infected subjects [38].

\section{Interleukin-8 (IL-8)}

IL-8 is produced by tumor cells, and has been implicated to play a role in cancer progression $[39,40]$. In the current study, no significant difference in the serum concentrations of circulating IL-8 between HIV+ NHL and NHL was observed (Figure 6). However, as compared to HIV+ cART patients, HIV+ NHL had significantly high serum concentrations of circulating 
IL-8 (Figure 6). In addition, NHL had high serum concentrations of circulating IL-8 as compared to the controls (Figure 6). These findings suggest that the serum concentrations of circulating IL-8 are increased in NHL regardless of the HIV status. It has been reported that the expression of IL- 8 correlates with the angiogenesis, tumorigenicity, and metastatic potential of many solid cancers [41].

It has also been suggested that targeting IL-8 signalling within the cancer cell micro-environment may assist in sensitizing cancer cells to conventional chemotherapy and novel treatment strategies [41]. In addition, Sharma et al. [42] showed that IL-8 is expressed in HIV associated lymphoma B-cell lines. Engel et al. [43] reported that viral IL-8 promotes lymphomagenesis through targeted recruitment of B-cells. Consistent with the current findings, Denizot et al. [34] showed that serum IL-8 concentrations are significantly higher in NHL patients as compared with the healthy controls. In the current study, the serum concentrations of circulating IL-8 were significantly increased in cART-naïve HIV+ patients as compared to HIV+ cART as well as when compared to the controls (Figure 6). This indicates that the serum concentrations of circulating IL-8 are increased in HIV+ state, and cART may reduce them. The serum concentrations of circulating IL-8 were negatively associated with the numbers of CD4 T-cells, CD19+ B-cells and NKT-cells in HIV+ patients (Table 1). In addition, the serum concentrations of circulating IL-8 were positively associated with CD8 T-cell activation (Table 1). It has been reported that the serum concentrations of IL-8 are elevated in the peripheral circulation of HIV-1 infected patients [44]. In a study by Lane et al. [45], it has been shown that IL-8 expression is increased in lymphatic micro-environment in HIV-1 infected patients and that inhibition of the activity of endogenous IL-8 markedly reduces HIV-1 replication. This suggests that IL- 8 may play a role in HIV-1 replication and disease progression.

\section{Interleukin-10 (IL-10)}

IL-10 is known to have multiple effects on B-cells, including stimulation of growth and differentiation $[46,47]$. In the current study, the serum concentrations of circulating IL-10 were significantly higher in HIV+ NHL as compared to HIV+ cART patients, however, there was no significant difference when HIV+ NHL patients were compared to NHL patients (Figure 7). In addition, NHL patients had increased serum concentrations of circulating IL-10 as compared to the controls (Figure 7). These findings suggest that the serum concentrations of circulating IL-10 are increased in HIV+ NHL patients. Voorzanger et al. [48] previously reported that HIV+ NHL may produce higher amounts of IL-10 than HIV negative NHL patients and HIV may be directly responsible for an increased IL-10 secretion. Consistent with the current findings, Gupta and colleagues [49], demonstrated that serum IL-10 concentrations are significantly higher in a subset of DLBCL patients as compared to controls and were correlated with adverse clinical features and shorter event free survival. The observed increased serum concentrations of circulating IL-10 may have contributed to the development of NHL. In a Multicenter AIDS Cohort Study, Breen et al. [50] showed that elevated serum IL-10 concentrations are associated with the development of lymphoma in HIV-1 infected individuals. In the same study, detectable serum IL-10 was seen much more frequently in lymphoma cases as compared to both HIV-1 infected patients and healthy controls [50]. Furthermore, in a study conducted by Edlefsen et al. [51], the increased risk of DLBCL development was observed in women with increased IL-10 expression. In addition, it has been previously shown that IL-10 production contributes to the clinical course of DLBCL and this phenomenon involves a substantial genetic component [47,52-54].

cART-naïve HIV+ patients had significantly higher serum concentrations of circulating IL-10 than both HIV+ cART patients and controls (Figure 7) in the current study. Thus, HIV-1 infection may have been a driving force to increased serum concentrations of circulating IL-10. The serum concentrations of circulating IL10 are greatly increased in cART-naïve HIV+ patients by nearly 4 fold. cART initiation decreased the serum concentrations of circulating IL-10 in HIV+ patients. The increased serum concentrations of circulating IL-10 were positively associated with the numbers of NK-cells and T-cell activation (Table 1). In consistence with the current findings, Brockman and Colleagues [55] showed that IL-10 mRNA expression and plasma IL10 concentrations were increased in the setting of chronic uncontrolled HIV-1 infection and were correlated with plasma viremia. In the same study, both IL-10 mRNA expression and plasma concentrations were reduced through successful cART treatment [55].

\section{Interleukin-12p70 (IL-12p70)}

IL-12p70 plays an important role in anti-tumor activities $[56,57]$.The serum concentrations of circulating IL-12p70 were investigated in the current study. No statistical significant difference in the serum concentrations of circulating IL-12p70 between HIV+ NHL and NHL patients was found (Figure 8). However, there was a trend towards increased serum concentrations of circulating IL-12p70 in NHL. In addition, HIV+ NHL had significantly lower serum concentrations of circulating IL-12p70 as compared to HIV+ cART patients (Figure 8). These findings suggest that the serum concentrations of circulating IL-12p70 are decreased in HIV+ NHL, and this may result in decreased anti-tumor activity against malignant lymphoma cells leading to its pathogenesis and progression.

As compared to the controls, NHL patients had increased serum concentrations of circulating IL-12p70 (Figure 8). In HIV negative NHL, anti-tumor activities are required to destroy malignant lymphoma cells, thus the increased serum 
concentrations of circulating IL-12p70 indicate increased antitumor activities which is beneficial for these patients. There was no significant difference in the serum concentrations of circulating IL-12p70 between HIV+ cART and cART-naïve HIV+ (Figure 8). cART-naïve HIV+ patients had increased serum concentrations of circulating IL-12p70 as compared to the controls (Figure 8). These results suggest that the serum concentrations of circulating IL-12p70 are increased in untreated HIV+ patients. Consistent with the current findings, Rockstroh et al. [58] showed that serum IL-12p70 concentrations are significantly increased in HIV-1 infected patients as compared to healthy controls. IL-12p70 may be playing a role in the eradication of HIV-1 virus. In a study by Roberts et al. [59], it was shown that higher concentrations of IL-12p70 observed in HIV-1 infected patients are associated with lower viral load.

The serum concentrations of circulating IL-12p70 were negatively associated with the numbers of CD4 T-cells, CD19+ B-cells, and FoxP3 expression (Table 1while they were positively associated with the numbers of CD8 T-cells, NK-cells, and CD8+CD38 expression (Table 1) in the current study. IL-12p70 is known to play a critical role in the generation of cell mediated immune responses to infectious agents including HIV-1 [60], thus the association of IL-12p70 with the numbers of CD8 T-cells and NK-cells observed in the current study confirm this role. IL-12p70 may stimulate the activities of CD8 and NK-cells as confirmed by positive correlation of IL-12p70 with increased CD8+CD38 expression. This may also explain the increased serum concentrations of circulating IL-12p70 in NHL patients observed in the present study which may increase cell mediated immunity against lymphoma cells.

\section{Interleukin-13 (IL-13)}

IL-13 enhances antigen presentation in HIV-1 infected patients, and induces the differentiation and function of macrophages [61,62]. IL-13 stimulates B-cell growth and immunoglobulin class switching of B-cells [63]. In the current study, the serum concentrations of circulating IL-13 were investigated. No statistical significant difference was observed in the serum concentrations of circulating IL-13 between HIV+ NHL and NHL as well as when HIV+ NHL were compared to HIV+ cART patients (Figure 9). However, NHL patients had increased serum concentrations of circulating IL-13 as compared to the controls (Figure 9). It has been reported that IL-13 expression is increased in NHL patients and may provide growth and survival advantage to B-cell NHL [64]. These findings suggest that the increased serum concentrations of circulating IL-13 may have increased the growth of B-cells in NHL patients. HIV-1 infection did not influence the serum concentrations of circulating IL-13 in NHL groups.

Furthermore, no significant difference was found in the serum concentrations of circulating IL-13 between HIV+ cART and cART-naïve HIV+ patients (Figure 9). However, cART-naïve
HIV+ patients had increased serum concentrations of circulating IL-13 as compared to the controls (Figure 9). These results indicate that the serum concentrations of circulating IL-13 are increased in untreated HIV+ patients. The serum concentrations of circulating IL-13 were negatively associated with the numbers of CD4 T-cells, while they correlated positively with CD8+CD38 expression (Table 1). It has been shown that IL-13 activates CD8 T-cells and NK-cells and increases HIV-1 specific cell mediated responses $[65,66]$, therefore, the observed increased serum concentrations of circulating IL-13 in cART-naïve HIV+ patients may have been triggered by HIV-1 virus. By increasing HIV-1 specific cell mediated immune responses, IL-13 may reduce the viral load. Montaner et al. [67] reported that IL-13 suppresses HIV-1 infection within monocytes and macrophages in vivo. The increased serum concentrations of circulating IL-13 were positively correlated with increased CD8+CD38 in the current study, confirming that IL-13 enhances CD8 T-cell activation. Thus, the serum concentrations of circulating IL-13 may have increased with increasing T-cell activation which resulted in the reduction in CD4 T-cell counts.

\section{Tumor necrosis factor- $\alpha$ (TNF- $\alpha$ )}

TNF- $\alpha$ is involved in pathological processes such as chronic inflammation, autoimmunity and malignant diseases [68]. In the current study, the serum concentrations of circulating TNF- $\alpha$ were investigated in HIV+ NHL patients. The serum concentrations of circulating TNF- $\alpha$ were significantly increased in HIV+ NHL patients as compared to NHL patients (Figure 10). However, no significant difference in TNF- $\alpha$ was found between HIV+ NHL and HIV+ cART patients. In addition, NHL patients had increased serum concentrations of circulating TNF- $\alpha$ as compared to the controls (Figure 10). It has been previously shown that genetic polymorphism leading to increased TNF- $\alpha$ production influences the clinical outcome of NHL and suggest a pathophysiological role for the genetic control of the immune response in lymphomas $[69,70]$. In addition, it has been shown that patients with malignant lymphomas have high circulating concentrations of TNF- $\alpha$ and that higher plasma concentrations of TNF- $\alpha$ are associated with poor disease outcome $[69,71]$. cART-naïve HIV+ patients had significantly high serum concentrations of circulating TNF- $\alpha$ as compared to the HIV+ cART patients as well as when compared to the controls (Figure 10). These results confirm that TNF- $\alpha$ is increased in HIV+ patients, while cART decreased the serum concentrations of circulating TNF- $\alpha$ to almost the level of the control population. The serum concentrations of circulating TNF- $\alpha$ were increased in NHL without HIV-1 infection.

The increased serum concentrations of circulating TNF- $\alpha$ were negatively associated with the numbers of CD4 T-cells, CD19+ B-cells, and FoxP3 expression, while they correlated positively with the numbers of CD8 T-cells, NK-cells and CD8+CD38 expression (Table 1). In addition, TNF- $\alpha$ was 
independently associated with HIV+ NHL. It has been previously shown that HIV-1 infection induces TNF- $\alpha$ expression, and the increased TNF- $\alpha$ expression is associated with increased viral replication, depletion of CD4 T-cell counts and poor outcome in HIV-1 infected patients [72]. It has also been reported that the expression of TNF- $\alpha$ is greatly increased in HIV-1 infection and that these levels increase with disease progression $[17,21,73]$. HIV-1 induces TNF- $\alpha$ expression, and exogenous TNF- $\alpha$ enhances HIV-1 replication and positive correlation between increased serum concentrations of TNF- $\alpha$ and increased plasma HIV-1 viral load have been demonstrated [17].

\section{Conclusion}

HIV-1 infection is associated with dysregulation of cytokine production and this is thought to contribute to HIV associated immune deficiency $[21,74]$. It has been reported that decreased secretion of specific cytokines and increased production of others contributes to the progression of HIV-1 associated immune deficiency [21]. The dysregulation of cytokine production may be playing a role in the pathogenesis of HIV+ NHL, as evidenced by increased prevalence of NHL in HIV-1 infection.

In the current study, the concentrations of inflammatory cytokines were increased in HIV+ NHL. This may have been a carry-over effect from increased concentrations observed in HIV+ patients and may have been caused by HIV-1 infection. However, high serum concentrations of circulating inflammatory cytokine were also observed in HIV negative NHL patients. This may have been caused by the presence of Epstein-Barr Virus (EBV) in these NHL patients or immune surveillance against malignant lymphoma cells. cART partially decreased the serum concentrations of circulating inflammatory cytokines. Thus in the current study, cART reversed the abnormal cytokine profile and this may contribute to suppression of HIV-1 replication and restoration of CD4 T-cell counts.

The decreased concentrations of inflammatory cytokines that was observed following cART initiation, may have resulted primarily from the virological suppression of HIV-1 virus mediated by cART. It is evident that local inflammatory processes and antigenic drive by HIV-1 can promote lymphomagenesis at the site of inflammation and chronic immune activation [7]. Cytokines play an important role in the pathogenesis of lymphomas and may contribute to the clinical manifestations in HIV+ NHL [75].

\section{Acknowledgement}

This study was financially supported by Harry Crossley foundation research grant, Columbia-South Africa (D43) training program for Research on HIV-associated malignancies and the joint National Research Foundation-German DFG-IRTG project 1522 "HIV/AIDS and Associated Infectious Diseases in Southern Africa“ (NRF-IRTG). We acknowledge Synexa Life Science laboratory where sample analysis was conducted.

\section{References}

1. Wiggill TM, Mayne ES, Willem P (2013) Challenges in lymphoma diagnosis in HIV positive patients in the South African setting. Transfus Apher Sci 49(2): 157-162.

2. Gopal S, Achenbach CJ, Yanik EL, Dittmer DP, Eron JJ, et al. (2014) Moving forward in HIV-associated cancer. J Clin Oncol 32(9): 876-880.

3. Opie J (2012) Haematological complications of HIV infection. S Afr Med J 102(6): 465-468.

4. Grivennikov SI, Greten FR, Karin M (2010) Immunity, inflammation, and cancer. Cell 140(6): 883-899.

5. Diakos CI, Charles KA, McMillan DC, Clarke SJ (2014) Cancer-related inflammation and treatment effectiveness. Lancet Oncol 15(11): e493-e503.

6. Mantovani A, Allavena P, Sica A, Balkwill F (2008) Cancer-related inflammation. Nature 454(7203): 436-444.

7. Baecklund E, Smedby KE, Sutton LA, Askling J, Rosenquist R (2014) Lymphoma development in patients with autoimmune and inflammatory disorders-what are the driving forces? Semin Cancer Biol 24: 61-70.

8. Frucht DM, Fukao T, Bogdan C, Schindler H, O'Shea JJ, et al. (2001) IFNgamma production by antigen-presenting cells: mechanisms emerge. Trends Immunol 22(10): 556-560.

9. Hu X, Ivashkiv LB (2009) Cross-regulation of signaling pathways by interferon-gamma: implications for immune responses and autoimmune diseases. Immunity 31(4):539-550.

10. Roff SR, Noon-Song EN, Yamamoto JK (2014) The Significance of Interferon- $\gamma$ in HIV-1 Pathogenesis, Therapy, and Prophylaxis. Front Immunol 4: 498.

11. Bax HI, Freeman AF, Anderson VL, Vesterhus P, Laerum D, et al. (2013) $\mathrm{B}$-cell lymphoma in a patient with complete interferon gamma receptor 1 deficiency. J Clin Immunol 33(6):1062-1066.

12. Gergely L, Aleksza M, Váróczy L, Ponyi A, Sipka S, et al. (2004) Intracellular IL-4/IFN-gamma producing peripheral $\mathrm{T}$ lymphocyte subsets in B cell non-Hodgkin's lymphoma patients. Eur J Haematol 72(5): 336-341.

13. Krause K, Metz M, Makris M, Zuberbier T, Maurer M (2012) The role of interleukin-1 in allergy-related disorders. Curr Opin Allergy Clin Immunol 12(5): 477-484.

14. Karimbux NY, Saraiya VM, Elangovan S, Allareddy V, Kinnunen T, et al. (2012) Interleukin-1 gene polymorphisms and chronic periodontitis in adult whites: a systematic review and meta-analysis. J Periodontol 83(11): 1407-1419.

15. Guo H, Gao J, Taxman DJ, Ting JP, Su L (2014) HIV-1 infection induces interleukin-1 $\beta$ production via TLR8 protein-dependent and NLRP3 inflammasome mechanisms in human monocytes. J Biol Chem 289(31): 21716-21726.

16. Corley PA (2000) Interleukin-1 receptor antagonist as a treatment of HIV infection. Med Hypotheses 54(4): 513-518.

17. Connolly NC, Riddler SA, Rinaldo CR (2005) Proinflammatory cytokines in HIV disease-a review and ationale for new therapeutic approaches. AIDS Rev 7(3): 168-180.

18. Sadeghi HM, Weiss L, Kazatchkine MD, Haeffner-Cavaillon N (1995) Antiretroviral therapy suppresses the constitutive production of interleukin-1 associated with human immunodeficiency virus infection. J Infect Dis 172(2): 547-550.

19. Mamik MK, Banerjee S, Walseth TF, Hirte R, Tang L, et al. (2011) HIV-1 and IL-1 $\beta$ regulate astrocytic CD38 through mitogen-activated 
protein kinases and nuclear factor- $\kappa \mathrm{B}$ signaling mechanisms. J Neuroinflammation 8: 145.

20. De Paoli P (2001) Immunological effects of interleukin-2 therapy in human immunodeficiency virus-positive subjects. Clin Diagn Lab Immunol 8(4): 671-677.

21. Kedzierska K, Crowe SM (2001) Cytokines and HIV-1: interactions and clinical implications. Antivir Chem Chemother 12(3): 133-150.

22. David D, Bani l, Moreau JL, Treilhou MP, Nakarai T, et al. (1998) Regulatory dysfunction of the interleukin-2 receptor during HIV infection and the impact of triple combination therapy. Proc Natl Acad Sci U S A 95(19): 11348-11353.

23. de Lastours V, LeGoff J, Brière J, Agbalika F, Boulet T, et al. (2014) Lymphoma and Epstein-Barr virus DNA in blood during interleukin-2 therapy in antiretroviral-naïve HIV-1-infected patients: a substudy of the ANRS 119 trial. HIV Med 15(1): 23-29.

24. Cozen W, Gill PS, Salam MT, Nieters A, Masood R, et al. (2008) Interleukin-2, interleukin-12, and interferon-gamma levels and risk of young adult Hodgkin lymphoma. Blood 111(7): 3377-3382.

25. Vento S, Cainelli F, Temesgen Z (2006) Interleukin-2 therapy and CD4+ T cells in HIV-1 infection. Lancet 367(9505): 93-95.

26. Molina JM, Levy Y, Fournier I, Hamonic S, Bentata M, et al. (2009) Interleukin-2 before antiretroviral therapy in patients with HIV infection: a randomized trial (ANRS 119). J Infect Dis 200(2): 206-215.

27. Shah MH, Baiocchi RA, Fehniger TA, Khatri VP, Gould M, et al. (2000) Cytokine replacement in patients with HIV-1 non-Hodgkin's lymphoma: the rationale for low-dose interleukin-2 therapy. Cancer J Sci Am 6 (Suppl 1): S45-s51.

28. Zamorano j, Rivas MD, Perez G (2003) Interleukin-4: A multifunctional cytokine. Immunologia 22(2): 215-224.

29. Lundin j, Kimby e, Bergmann l, Karakas T, Mellstedt H, et al. (2001) Interleukin 4 therapy for patients with chronic lymphocytic leukaemia: a phase I/II study. Br J Haematol 112(1): 155-160.

30. Valentin a, Lu w, Rosati M, Schneider R, Albert J, et al. (1998) Dual effect of interleukin 4 on HIV-1 expression: implications for viral phenotypic switch and disease progression. Proc Natl Acad Sci U S A 95(15): 88868891.

31. Kazazi F, Mathijs JM, Chang J, et al. (1992) Recombinant interleukin 4 stimulates human immunodeficiency virus production by infected monocytes and macrophages. J Gen Virol 73(Pt 4): 941-949.

32. Zarogoulidis P, Yarmus L, Darwiche K, Walter R, Huang H, et al. (2013) Interleukin-6 cytokine: a multifunctional glycoprotein for cancer. Immunome Res 9(62): 16535.

33. Pluda JM, Venzon DJ, Tosato G, et al. (1993) Parameters affecting the development of non-Hodgkin's lymphoma in patients with severe human immunodeficiency virus infection receiving antiretroviral therapy. J Clin Oncol 11(6): 1099-1107.

34. Denizot Y, Fixe P, Liozon E, Praloran P (1996) Serum interleukin-8 (IL$8)$ and IL-6 concentrations in patients with hematologic malignancies. Blood 87(9): 4016-4017.

35. Poli G, Bressler P, Kinter A, Duh E, Timmer WC, et al. (1990) Interleukin-6 induces human immunodeficiency virus expression in infected monocytic cells alone and in synergy with tumor necrosis factor-a by transcriptional and post-transcriptional mechanisms. J Exp Med 172(1): 151-158.

36. Hosein S (2012) Treatment Update 193. CATIE 24(7).

37. Ullum H, Diamant M, Victor J, Gøtzsche PC, Bendtzen K, et al. (1996) Increased circulating levels of interleukin-6 in HIV-seropositive subjects. J Acquir Immune Defic Syndr Hum Retrovirol 13(1): 93-94.
38. Poli G, Fauci AS (1995) Role of cytokines in the pathogenesis of human immunodeficiency virus infection. In: Aggarwal BB, Puri RK (Eds.) Human cytokines and their role in health and human disease. Blackwell, Cambridge, USA, pp. 421-450.

39. Xie K (2001) Interleukin-8 and human cancer biology. Cytokine Growth Factor Rev 12(4): 375-391.

40. Campbell LM, Maxwell PJ, Waugh DJ (2013) Rationale and Means to Target Pro-Inflammatory Interleukin-8 (CXCL8) Signaling in Cancer. Pharmaceuticals (Basel) 6(8): 929-959.

41. Waugh DJ, Wilson C (2008) The interleukin-8 pathway in cancer. Clin Cancer Res 14(21): 6735-6741.

42. Sharma V, Zhang L (2001) Interleukin-8 expression in AIDS-associated lymphoma B-cell lines. Biochem Biophys Res Commun 282(2): 369375 .

43. Engel AT, Selvaraj RK, Kamil JP, Osterrieder N, Kaufer BB (2012) Marek's disease viral interleukin-8 promotes lymphoma formation through targeted recruitment of B cells and CD4+ CD25+ T cells. J Virol 86(16): 8536-8545.

44. Taylor SM (1998) The role of interleukin-8 in the immunopathogenesis of hiv-1 disease and tuberculosis.

45. Lane BR, Lore K, Bock PJ, Andersson J, Coffey MJ, et al. (2001) Interleukin-8 stimulates human immunodeficiency virus type 1 replication and is a potential new target for antiretroviral therapy. J Virol 75(17): 8195-8202.

46. Blay JY, Burdin N, Rousset P, Lenoir G, Biron P, et al. (1993) Serum interleukin-10 in non-Hodgkin's lymphoma: a prognostic factor. Blood 82(7): 2169-2174.

47. Masood R, Zhang Y, Bond MW, Scadden DT, Moudgil T, et al. (1995) Interleukin-10 is an autocrine growth factor for acquired immunodeficiency syndrome-related B-cell lymphoma. Blood 85(12): 3423-3430.

48. Voorzanger N, Blay JY (1996) Interleukin 10 and non-Hodgkin's lymphomas. Cancer in Transplantation: Prevention and Treatment. Springer Netherlands 27: 229-241.

49. Gupta M, Han JJ, Stenson M, Maurer M, Wellik L, et al. (2012) Elevated serum IL-10 levels in diffuse large B-cell lymphoma: a mechanism of aberrant JAK2 activation. Blood 119(12): 2844-2853.

50. Breen EC, Boscardin WJ, Detels R (2003) Non-Hodgkin's B cell lymphoma in persons with acquired immunodeficiency syndrome is associated with increased serum levels of IL10, or the IL10 promoter -592 C/C genotype. Clin Immunol 109(2):119-129.

51. Edlefsen KL, O Martínez-Maza, Madeleine MM, Magpantay L, Mirick $\mathrm{DK}$, et al. (2014) Cytokines in serum in relation to future non-Hodgkin lymphoma risk: evidence for associations by histologic subtype. Int J Cancer 135(4): 913-922.

52. Lech-Maranda E, Baseggio L, Bienvenu J, Charlot C, Berger F, et al. (2004) Interleukin-10 gene promoter polymorphisms influence the clinical outcome of diffuse large B-cell lymphoma. Blood 103(9): 3529-3534.

53. Bogunia-Kubik K, Mazur G, Wróbel T, Kuliczkowski K, Lange A (2008) Interleukin-10 gene polymorphisms influence the clinical course of non-Hodgkin's lymphoma. Tissue Antigens 71(2): 146-150.

54. Hosgood HD, Au WY, Kim HN, Liu J, Hu W, et al. (2013) IL10 and TNF variants and risk of non-Hodgkin lymphoma among three Asian populations. Int J Hematol 97(6): 793-799.

55. Brockman MA, Kwon DS, Tighe DP, Pavlik DF, Rosato PC, et al. (2009) IL10 is up-regulated in multiple cell types during viremic HIV infection and reversibly inhibits virus-specific T cells. Blood 114(2): 346-356. 
56. Toubai T, Tanaka J, Ota S, Fukuhara T, Hashino S, et al. (2006) Effect of granulocyte colony-stimulating factor on IL-12 p40 production during chemotherapy for B-cell lineage non-Hodgkin's lymphoma patients. Eur J Haematol 77(5): 403-409.

57. Pan WY, Lo CH, Chen CC, Wu PY, Roffler SR, et al. (2012) Cancer immunotherapy using a membrane-bound interleukin-12 with B7-1 transmembrane and cytoplasmic domains. Mol Ther 20(5): 927-937.

58. Rockstroh JK, Kreuzer KA, Sauerbruch T, Spengler U (1998) Protein levels of interleukin-12 p70 holomer, its p40 chain and interferongamma during advancing HIV infection. J Infect 37(3): 282-286.

59. Roberts L, Passmore JA, Williamson C, Little F, Bebell LM, et al. (2010) Plasma cytokine levels during acute HIV-1 infection predict HIV disease progression. AIDS 24(6): 819-831.

60. Guzzo C, Mat NFC, Zhang X, Gee K (2011) Impact of HIV Infection and HAART Therapy on CD4 T Helper Cell Subset Expression and Function, HIV-Host Interactions. INTECH.

61. Bailer RT, Holloway A, Sun J, Margolick JB, Martin M, et al. (1999) IL13 and IFN-gamma secretion by activated T cells in HIV-1 infection associated with viral suppression and a lack of disease progression. J Immunol 162(12): 7534-7542.

62. Jensen PL (2000) The interleukin 13 receptor complex. Stem Cells 18(1): 61-62.

63. Skinnider BF, Elia AJ, Gascoyne RD, Trümper LH, von Bonin F, et al (2001) Interleukin 13 and interleukin 13 receptor are frequently expressed by Hodgkin and Reed-Sternberg cells of Hodgkin lymphoma. Blood 97(1): 250-255.

64. Billard C, Caput D, Vita N, Ferrara P, Orrico M, et al. (1997) Interleukin-13 responsiveness and interleukin-13 receptor expression in nonHodgkin's lymphoma and reactive lymph node B cells. Modulation by CD40 activation. Eur Cytokine Netw 8(1): 19-27.

65. Emilie D, Zou W, Fior R, Durandy A, Crevon MC, et al. (1997) Production and roles of IL-6, IL-10, and IL-13 in B-lymphocyte malignancies and in B-lymphocyte hyperactivity of HIV infection and autoimmunity. Methods11(1): 133-142.
66. Papasavvas E, Sun J, Luo Q Moore EC, Thiel B, et al. (2005) IL-13 acutely augments HIV-specific and recall responses from HIV-1infected subjects in vitro by modulating monocytes. J Immunol 175(8): 5532-5540.

67. Montaner LJ, Doyle AG, Collin M, Herbein G, Illei P, et al. (1993) Interleukin 13 inhibits human immunodeficiency virus type 1 production in primary blood-derived human macrophages in vitro. J Exp Med 178(2): 743-747.

68. Balkwill F (2006) TNF-alpha in promotion and progression of cancer. Cancer Metastasis Rev 25(3): 409-416.

69. Warzocha K, Ribeiro P, Bienvenu J, Roy P, Charlot C, et al. (1998) Genetic polymorphisms in the tumor necrosis factor locus influence non-Hodgkin's lymphoma outcome. Blood 91(10): 3574-3581.

70. Ibrahim A, Abdel Rahman H, Khorshied M, Sami R, Nasr N, et al. (2012) Tumor necrosis factor alpha-308 and Lymphotoxin alpha+252 genetic polymorphisms and the susceptibility to non-Hodgkin lymphoma in Egypt. Leuk Res 36(6): 694-698.

71. Salles g, Bienvenu J, Bastion Y, Barbier Y, Doche C, et al. (1996) Elevated circulating levels of TNFalpha and its p55 soluble receptor are associated with an adverse prognosis in lymphoma patients. $\mathrm{Br}$ Haematol 93(2): 352-359.

72. Kumar A, Abbas W, Herbein G (2013) TNF and TNF receptor superfamily members in HIV infection: new cellular targets for therapy? Mediators Inflamm 2013: 484378.

73. Ownby RL, Kumar AM, Benny Fernandez J, Moleon-Borodowsky I, Gonzalez L, et al. (2009) Tumor necrosis factor-alpha levels in HIV-1 seropositive injecting drug users. J Neuroimmune Pharmacol 4(3): 350-358.

74. Shebl FM, Yu K, Landgren 0, Goedert JJ, Rabkin CS (2012) Increased levels of circulating cytokines with HIV-related immunosuppression. AIDS Res Hum Retroviruses 28(8): 809-815.

75. Talaat RM, Abdel-Aziz AM, El-Maadawy EA (2014) Interleukin 10 gene promoter polymorphism and risk of diffuse large B cell lymphoma (DLBCL). Egyptian Journal of Medical Human Genetics 15(1): 7-13.

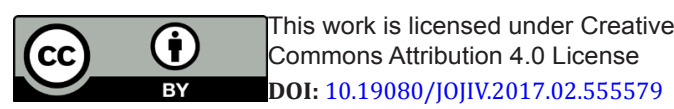

\begin{tabular}{l} 
Your next submission with Juniper Publishers \\
will reach you the below assets \\
- Quality Editorial service \\
- Swift Peer Review \\
- Reprints availability \\
- E-prints Service \\
- Manuscript Podcast for convenient understanding \\
- Global attainment for your research \\
- Manuscript accessibility in different formats \\
( Pdf, E-pub, Full Text, Audio) \\
- Unceasing customer service \\
Track the below URL for one-step submission \\
https://juniperpublishers.com/online-submission.php \\
\hline
\end{tabular}

